RESEARCH REPORT

\title{
Effects of education and other socioeconomic factors on middle age mortality in rural Bangladesh
}

\author{
L S Hurt, C Ronsmans, S Saha
}

J Epidemiol Community Health 2004;58:315-320. doi: 10.1136/jech.2003.007351

See end of article for authors' affiliations

....................

Correspondence to: Dr L S Hurt, Maternal Health Programme, Department of Infectious and Tropical Diseases, London School of Hygiene and Tropical Medicine, London WCIE 7HT, UK; lisa.hurł@|shtm.ac.uk

Accepted for publication 21 May 2003
Study objective: To examine socioeconomic gradients in mortality in adult women and their husbands in Bangladesh, paying particular attention to the independent effects of the educational status of each spouse. Design: Historical cohort study.

Setting: Matlab, a rural area $60 \mathrm{~km}$ south east of Dhaka, the capital of Bangladesh.

Participants: 14803 married women aged 45 or over and their husbands who were resident in the Matlab Demographic Surveillance area between 30 June 1982 and 31 December 1998.

Main results: Mortality was lower in women with formal or Koranic education compared with those with none (adjusted rate ratio for formal education $=0.68,95 \% \mathrm{Cl} 0.53$ to 0.86 ; adjusted rate ratio for Koranic schooling $=0.82,95 \% \mathrm{Cl} 0.66$ to 1.00 ). After adjusting for her own education, the husband's level of education or occupation did not have an independent effect on a woman's survival. Men who had attended formal education had lower mortality than those without any education (adjusted rate ratio $=0.84,95 \% \mathrm{Cl} 0.75$ to 0.93 ), but men whose wives had been educated had an additional survival advantage independent of their own education and occupation (adjusted rate ratio $=0.76,95 \% \mathrm{Cl} 0.67$ to $0.87)$. Mortality in both sexes was also significantly associated with marital status and the percentage of surviving children, and in men was associated with the man's occupation, religion, area of residence.

Conclusions: The data suggest that socioeconomic status has a strong influence on mortality in adults in Bangladesh. They also illustrate how important the continued promotion of education, particularly for women, may be for the survival of both women and men in rural Bangladesh. dition has long been recognised that people who are socially disadvantaged have higher mortality. Social or economic gradients in adult mortality have consistently been observed in affluent societies ${ }^{12}$ and studies in the developing world have also found substantial inequalities. ${ }^{3-9}$ Increasing attention is now being paid to understanding the nature of such inequalities and the pathways through which they exert their effects. ${ }^{10}$

One of the critical factors in this pathway is adult education. In affluent societies, a consistent association between the educational status of adults and their mortality has been shown, independent of other social or economic factors. ${ }^{11-14}$ Effects are seen in both women and men, although they might be slightly weaker in women than in men. ${ }^{15} 16$ Factors thought to contribute to the lower mortality of educated people are improvements in their employment opportunities and material circumstances, and an increased knowledge about health matters with consequent reductions in risky health behaviours. ${ }^{11} 13$ 17-20

Evidence is also accruing that educated men and women in the developing world have lower mortality, but the mechanisms underlying this association are not fully understood..$^{7-9}$ Understanding social inequalities in developing countries may require looking into the independent effects of individuals within households over and above those between households, partly because women's and men's roles within a household are so distinct. ${ }^{21}$ Studies examining the determinants of child mortality and fertility, for example, have shown maternal education to be more decisive than the educational status of the father. ${ }^{22-25}$ In this study, we examine socioeconomic gradients in mortality in adult women and their husbands in rural Bangladesh, paying particular attention to the independent effects of the educational status of each spouse.

\section{METHODS}

\section{Study population}

This historical cohort study was conducted in Matlab, a rural area 60 kilometres south east of Dhaka, the capital of Bangladesh. Matlab is typical of the delta areas of rural Bangladesh. The population is predominantly Muslim, and the main sources of income are farming and fishing. Marriage is almost universal and polygamy is rare. Women's social status is directly tied to the institution of purdah and women have generally little control over resources other than through their association with men. ${ }^{26}$

The area is divided into an intervention area, where the International Centre for Diarrhoeal Disease Research, Bangladesh: Centre for Health and Population Research (ICDDR,B) has coordinated a variety of health initiatives, and a comparison area where health services are provided by the Bangladeshi government. Most interventions have targeted children, such as immunisation and common childhood illnesses. Interventions aimed at adults are uncommon, except for family planning and safe motherhood programmes and interventions aimed at preventing and treating diarrhoeal diseases. ${ }^{27}$

\section{Data sources and study cohort}

Since 1966, the ICDDR, B has managed a health and demographic surveillance system (HDSS) in the study area, covering a population of $200000 .{ }^{28}$ All pregnancy outcomes, deaths, marriages, and migrations are recorded monthly, with literate female community health research workers

\footnotetext{
Abbreviations: ICDDR, B, International Centre for Diarrhoeal Disease Research, Bangladesh: Centre for Health and Population Research; CHRW, community health research worker
} 
(CHRWs) visiting every house in each village to record events. Each CHRW is resident in the area in which she works and covers a population of around 1000 people. Every two months, senior health assistants accompany the CHRWs to the villages, to verify the data collected. During these visits, specific details about each vital event are obtained through interviews with family members. Periodic censuses are used to supplement the demographic data with socioeconomic information. Data from the 1982 census were used for this study. A unique identification number is assigned to each person under surveillance. This allows for linkage of information between the demographic and socioeconomic data, and between members of the same family.

The cohort was selected as part of a study examining the association between fertility and mortality in women and men who had completed their reproductive life. ${ }^{29}$ The cohorts used here consist of ever-married women aged 45 or over and their husbands. Women were included if they were 45 to 55 on 30 June 1982 (census day), became 45 between 30 June 1982 and 31 December 1998, or were 45 to 55 when they migrated into the area during that period, and if their husbands were alive and resident in the area on the day their wives entered the cohort. The husbands of these women entered the cohort on the same day as their wives. Both the women and the men were followed up until they died, migrated, or until 31 December 1998.

We obtained indicators of social status, including religion, education, and occupation from the 1982 census. Educational status was categorised as none, Koranic, or formal (any, and one to four, or five or more years). Male occupation was grouped as skilled (such as teachers, tailors, barbers, or salesmen), unskilled (such as farm labourers or fishermen), none, or disabled (physical or mental illness that prevented them from working), in accordance with the definitions used by the ICDDR, B. Details of area of residence, marital status, age, reproductive history, migration, and mortality were obtained from the monthly surveillance records. We also computed the percentage of children born alive who were surviving at the time the woman entered the cohort, as the proportion of children surviving is thought to be an important indicator of socioeconomic status in rural Bangladesh. ${ }^{8}{ }^{\circ 0}$

\section{Statistical analyses}

We calculated person years of observation from the entry date until the subject died, migrated, or the end of the study. Age, time period, and marital status were treated as time varying covariates. We used hotdeck imputation ${ }^{31}$ to control for missing data on female education in $1 \%$ of women and male education and occupation in $4 \%$ of men, and multiple imputation $^{31} 32$ to control for missing reproductive histories in $6 \%$ of subjects. Sensitivity analyses showed that the conclusions did not change after imputation. ${ }^{29}$ Poisson regression was used to calculate crude and adjusted rate ratios, assessing statistical significance using the likelihood ratio test and the Wald test for linear trends. The imputations were conducted using Solas version 2.0 (Cork, Ireland), and the Poisson regression using Stata version 6.0 (College Station, TX, USA). All analyses are presented separately for women and men.

\section{RESULTS}

There were 14803 women in the sample, with a mean age at entry of 46.5 (SD 2.6). They had, on average, given birth to 7.3 children (SD 2.4), and the mean number surviving was

Table 1 Relation between education and other socioeconomic variables in both sexes

\begin{tabular}{|c|c|c|c|c|c|c|c|c|}
\hline & \multicolumn{4}{|l|}{ Women } & \multicolumn{4}{|l|}{ Men } \\
\hline & \multicolumn{4}{|c|}{ Educational status } & \multicolumn{4}{|c|}{ Educational status } \\
\hline & None \% & Koran*\% & Formal \% & Total numbert & None $\%$ & Koran \% & Formal \% & Total number \\
\hline Total & 19 & 59 & 22 & 14803 & 14 & 34 & 50 & 14803 \\
\hline \multicolumn{9}{|c|}{ Spouse's education } \\
\hline None & 78 & 16 & 5 & 2059 & 57 & 3 & 40 & 2823 \\
\hline $\begin{array}{l}\text { Koranic } \\
\text { education }\end{array}$ & 2 & 92 & 6 & 5182 & 4 & 55 & 42 & 8754 \\
\hline \multirow{2}{*}{$\begin{array}{l}\text { Formal } \\
\text { education }\end{array}$} & 15 & 48 & 37 & 7562 & 3 & 9 & 87 & 3226 \\
\hline & \multicolumn{4}{|c|}{$\chi^{2}$ statistic $2146, \mathrm{p}<0.0001 \ddagger$} & \multicolumn{4}{|c|}{$\chi^{2}$ statistic $2146, \mathrm{p}<0.0001$} \\
\hline \multicolumn{9}{|c|}{ 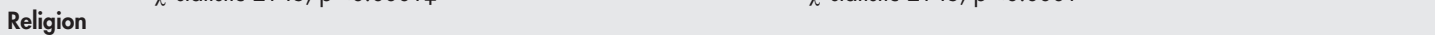 } \\
\hline Muslim & 8 & 68 & 22 & 12703 & 8 & 40 & 50 & 12703 \\
\hline \multirow{2}{*}{ Hindu } & 82 & 1 & 16 & 2100 & 47 & $<1$ & 52 & 2100 \\
\hline & \multicolumn{4}{|c|}{$\chi^{2}$ statistic $42, p<0.0001$} & \multicolumn{4}{|c|}{$\chi^{2}$ statistic $2, p=0.154$} \\
\hline \multicolumn{9}{|c|}{ Male occupation } \\
\hline Skilled & 18 & 50 & 31 & 4696 & 11 & 26 & 63 & 4696 \\
\hline Unskilled & 19 & 63 & 18 & 9780 & 15 & 39 & 46 & 9780 \\
\hline None & 21 & 58 & 21 & 131 & 31 & 31 & 38 & 131 \\
\hline \multirow[t]{2}{*}{ Disabled } & 20 & 63 & 17 & 196 & 17 & 41 & 42 & 196 \\
\hline & \multicolumn{4}{|c|}{$\chi^{2}$ statistic $309, \mathrm{p}<0.0001$} & \multicolumn{4}{|c|}{$\chi^{2}$ statistic $364, p<0.0001$} \\
\hline \multicolumn{9}{|c|}{ Area of residence } \\
\hline Intervention & 23 & 53 & 24 & 7656 & 16 & 30 & 52 & 7656 \\
\hline \multirow[t]{2}{*}{ Comparison } & 15 & 64 & 19 & 7147 & 11 & 39 & 48 & 7147 \\
\hline & \multicolumn{4}{|c|}{$\chi^{2}$ statistic $48, p<0.0001$} & \multirow{2}{*}{\multicolumn{4}{|c|}{$\chi^{2}$ statistic $17, \mathrm{p}<0.0001$}} \\
\hline \multicolumn{5}{|c|}{ Marital status at exit } & & & & \\
\hline Married & 17 & 58 & 25 & 9685 & 14 & 34 & 50 & 13743 \\
\hline Widowed & 22 & 61 & 17 & 5082 & 16 & 33 & 50 & 1024 \\
\hline \multirow[t]{2}{*}{ Divorced } & 6 & 83 & 11 & 36 & 6 & 44 & 50 & 36 \\
\hline & \multicolumn{4}{|c|}{$\chi^{2}$ statistic $128, p<0.0001$} & \multirow{2}{*}{\multicolumn{4}{|c|}{$\chi^{2}$ statistic $0.09, \mathrm{p}<0.958$}} \\
\hline \multicolumn{5}{|c|}{ Percentage of children surviving } & & & & \\
\hline $75.0-100$ & 18 & 56 & 26 & 8777 & 13 & 33 & 54 & 8777 \\
\hline $50.0-74.9$ & 20 & 63 & 17 & 4904 & 15 & 38 & 47 & 4904 \\
\hline \multirow[t]{2}{*}{$0-49.9$} & 21 & 68 & 12 & 1122 & 16 & 41 & 43 & 1122 \\
\hline & \multicolumn{4}{|c|}{$\chi^{2}$ statistic $219, \mathrm{p}<0.0001$} & \multicolumn{4}{|c|}{$\chi^{2}$ statistic $90, \mathrm{p}<0.0001$} \\
\hline
\end{tabular}

*Koranic schooling. †Percentages may not add up to $100 \%$ because of rounding. $¥$ Comparing subjects with any formal education with subject in both other educational groups. 
5.5 (SD 2.0). The 14803 men were, on average, 11 years older than their wives (mean age at entry 57.3, SD 5.5). Table 1 shows the relation between the person's education and other socioeconomic variables, presented separately for women and men.

Most women had received no education (19\%) or attended Koranic schooling (59\%), and only $22 \%$ had received formal education. Women were significantly more likely to have attended formal education if their husband had done so, if their husband was in a skilled occupation, if they were Muslim, if they lived in the intervention area, or if they were still married at the end of the study period. On the other hand, more than half of the men had received some formal education. Men in skilled occupations were more likely to have received any formal education, as were men in the intervention area.

There were 146668 person years of follow up in the female cohort (table 2 ). All cause mortality was 8.41 per 1000 person years. The most important determinant of adult female mortality was the woman's own educational attainment. Mortality was substantially lower in women who had attended any formal education compared with those with none (adjusted rate ratio $=0.68,95 \%$ CI 0.53 to 0.86 ) but even Koranic education conferred a substantial benefit (adjusted rate ratio $=0.82,95 \%$ CI 0.66 to 1.00 ). The husband's level of education or occupation did not have an independent effect on women's survival. Mortality was higher in women who became widowed during the study period, and was lower in women who had a high percentage of their children surviving when they entered the cohort. Mortality rates were also higher in women who became divorced, but the wide confidence intervals around the rate ratios (because of small numbers in this category) do not allow firm conclusions to be drawn. There were no statistically significant interactions between the socioeconomic variables. Specifically, there was no significant interaction between female and male education, or between age or religion and the other socioeconomic variables (data not shown).

Table 3 shows the association between socioeconomic status and all cause mortality in the men. There were 124498 person years of follow up in the men, and the crude mortality rate was 35.29 per 1000 person years (95\% CI 34.27 to 36.35). Mortality was higher in men than in women as the men were older than their wives and age specific mortality rates in Matlab are higher in men than women after age $45 .^{8}$

Men who had attended formal education had lower mortality than those without any education (adjusted rate ratio $=0.84,95 \%$ CI 0.75 to 0.93 ). Koranic schooling was not independently associated with mortality. Men whose wives had been educated, on the other hand, had an additional survival advantage, both if the wife had attended Koranic or formal education (adjusted rate ratios $=0.85,95 \%$ CI 0.76 to 0.96 and $0.76,95 \%$ CI 0.67 to 0.87 ). Disabled men, though they were few, had extremely high mortality rates. Mortality was also higher for men who had become widowed during the study period, those living in the comparison area and those who had lost many children. None of the interactions between the socioeconomic variables in the male data were of statistical significance (data not shown). In particular, there was no interaction between male and female education, or between age or religion and the other socioeconomic variables.

\section{DISCUSSION}

This study shows that mortality is significantly lower in educated adults in Matlab, even after adjusting for other measures of socioeconomic status. The effects of women's education are particularly noteworthy, as husbands with educated wives experience substantially lower mortality rates, independent of their own educational or occupational status. Male education, on the other hand, has no effect on

Table 2 Association between socioeconomic status and all cause mortality between 1982 and 1998 in women aged 45 to 71 in Matlab, Bangladesh who were married at entry

\begin{tabular}{|c|c|c|c|c|c|}
\hline Characteristic & Deaths & Person years & Crude rate* & Crude rate ratio $(95 \% \mathrm{Cl})$ & Adjusted rate ratio $(95 \% \mathrm{Cl}) \dagger$ \\
\hline \multicolumn{6}{|l|}{ Own education } \\
\hline None & 301 & 27226 & 11.06 & 1.00 & 1.00 \\
\hline Koranic education & 751 & 89821 & 8.36 & $0.76(0.66$ to 0.86$)$ & $0.82(0.66$ to 1.00$)$ \\
\hline Any formal & 181 & 29622 & 6.11 & $0.55(0.46$ to 0.66$)$ & $0.68(0.53$ to 0.86$)$ \\
\hline 1 to 4 years formal & 108 & 17147 & 6.30 & $0.57(0.46$ to 0.71$)$ & $0.67(0.52$ to 0.88$)$ \\
\hline 5+formal & 73 & 12475 & 5.85 & $0.52(0.41$ to 0.68$)$ & $0.69(0.51$ to 0.95$)$ \\
\hline \multicolumn{6}{|l|}{ Husband's education } \\
\hline None & 204 & 19444 & 10.49 & 1.00 & 1.00 \\
\hline Koranic education & 428 & 51586 & 8.30 & $0.79(0.67$ to 0.93$)$ & $0.94(0.75$ to 1.17$)$ \\
\hline Any formal & 601 & 75639 & 7.95 & $0.75(0.65$ to 0.89$)$ & $0.93(0.77$ to 1.13$)$ \\
\hline 1 to 4 years formal & 300 & 35807 & 8.38 & 0.80 (0.67 to 0.95$)$ & $0.94(0.76$ to 1.15$)$ \\
\hline $5+$ formal & 301 & 39832 & 7.56 & $0.72(0.60$ to 0.86$)$ & $0.92(0.74$ to 1.14$)$ \\
\hline \multicolumn{6}{|l|}{ Religion } \\
\hline Muslim & 1026 & 126996 & 8.08 & 1.00 & 1.00 \\
\hline Hindu & 207 & 19673 & 10.52 & $1.30(1.12$ to 1.51$)$ & $1.10(0.89$ to 1.36$)$ \\
\hline \multicolumn{6}{|l|}{ Male occupation } \\
\hline Skilled & 305 & 41295 & 7.39 & 0.85 (0.75 to 0.97$)$ & $1.04(0.91$ to 1.19$)$ \\
\hline Unskilled & 881 & 101698 & 8.66 & 1.00 & 1.00 \\
\hline None & 12 & 1269 & 9.46 & 1.09 (0.62 to 1.93$)$ & $0.99(0.56$ to 1.75$)$ \\
\hline Disabled & 35 & 2407 & 14.54 & $1.68(1.20$ to 2.35$)$ & $1.13(0.80$ to 1.59$)$ \\
\hline \multicolumn{6}{|l|}{ Area of residence } \\
\hline Intervention & 633 & 76270 & 8.30 & 1.00 & 1.00 \\
\hline Comparison & 600 & 70399 & 8.52 & $1.03(0.92$ to 1.15$)$ & $1.04(0.92$ to 1.16$)$ \\
\hline \multicolumn{6}{|l|}{ Marital status } \\
\hline Married & 848 & 120711 & 7.03 & 1.00 & 1.00 \\
\hline Widowed & 382 & 25756 & 14.83 & 2.11 (1.87 to 2.38$)$ & $1.22(1.07$ to 1.40$)$ \\
\hline Divorced & 3 & 202 & 14.85 & $2.12(0.68$ to 6.58$)$ & $1.61(0.52$ to 5.05$)$ \\
\hline \multicolumn{6}{|c|}{ Percentage of children surviving } \\
\hline $75.0-100$ & 542 & 83406 & 6.50 & 1.00 & 1.00 \\
\hline $50.0-74.9$ & 533 & 51167 & 10.42 & $1.60(1.42$ to 1.81$)$ & 1.52 (1.34 to 1.72$)$ \\
\hline $0-49.9$ & 158 & 12094 & 13.06 & 2.01 (1.67 to 2.41$)$ & $1.83(1.51$ to 2.20$)$ \\
\hline
\end{tabular}


their wife's mortality after adjusting for the wife's own education.

While the demographic data from the Matlab surveillance area are likely to be accurate and complete, ${ }^{28}$ caution is required in the interpretation of results. Firstly, the educational effects seen may, in part, reflect the economic advantages associated with education, rather than the effects of education in itself and the study may have been subject to residual confounding. ${ }^{22}$ Secondly, the sample consisted of a subgroup of women and their husbands and the way the samples were chosen may have affected the observed associations (selection bias).

The educational effects remained substantial even after accounting for important indicators of socioeconomic status in this population, such as religion, male occupation, and surviving children. ${ }^{83}$ Residual confounding is not a plausible explanation for the effects of formal education in women because in this setting formal education is unlikely to increase women's prospects of income or employment. Women in rural Bangladesh own very few assets and their movement is restricted outside the family compound. When they marry, they move in with their husband's family and, apart from the dowry that they bring with them, receive little financial support from their own family during their adult life. ${ }^{34}$ Elderly men, on the other hand, retain economic power either because they continue to work outside the home or by retaining ownership of household assets and there may have been some residual confounding related to formal education in men.

Selection bias may have occurred in a number of ways. Ever-married women who were widowed or divorced on entry or whose husband had migrated were not included in this sample. Women retained in the analysis were more likely to be educated (22\% compared with $19 \%$ ) and had slightly lower mortality. ${ }^{29}$ The results in the full cohort of women were remarkably similar to those in the sample presented

\section{Key points}

- Clear socioeconomic gradients in mortality have been shown in affluent societies.

- Socioeconomic status, and education in particular, has a strong influence on the mortality of adults in rural Bangladesh, where the population has no obvious means by which to influence their chances of survival.

- The effects of women's education are particularly noteworthy, as husbands with educated wives experience substantially lower mortality rates, independent of their own educational status.

- Male education has no effect on their wife's mortality after adjusting for the wife's own education.

- These data provide a powerful incentive for the continued promotion of formal education of women in this setting.

here however (data not shown), and selection bias is unlikely to explain the findings in women.

Selection bias may also be a potential issue in the men. Temporary migration of men from Matlab to Dhaka, India and the Middle East for work is comparatively common and such men were excluded from our analysis. Although we did not have information on the migrant men in our cohort, other studies have shown that migrants from rural Bangladesh tend to be more educated than non-migrants. ${ }^{35}{ }^{36}$ Migration of adult men may have positive effects on the decision making power and economic wellbeing of the women left behind. ${ }^{36}{ }^{37}$ Land ownership is also higher in migrant households, ${ }^{36}$ the household income tends to increase over time, and mortality is lower. ${ }^{35}$ The exclusion

Table 3 Association between socioeconomic status and all cause mortality between 1982 and 1998 in men aged 45 to 90 in Matlab, Bangladesh, who were married at entry

\begin{tabular}{|c|c|c|c|c|c|}
\hline Characteristic & Deaths & Person years & Crude rate* & Crude rate ratio $(95 \% \mathrm{Cl})$ & Adjusted rate ratio $(95 \% \mathrm{Cl}) \dagger$ \\
\hline \multicolumn{6}{|l|}{ Own education } \\
\hline None & 698 & 15895 & 43.91 & 1.00 & 1.00 \\
\hline Koranic education & 1605 & 43167 & 37.18 & 0.85 (0.77 to 0.93$)$ & $0.98(0.87$ to 1.11$)$ \\
\hline Any formal & 2092 & 65436 & 31.96 & 0.72 (0.67 to 0.79 ) & $0.84(0.75$ to 0.93$)$ \\
\hline 1 to 4 years formal & 1044 & 30267 & 34.49 & $0.79(0.71$ to 0.86$)$ & $0.88(0.79$ to 0.98$)$ \\
\hline \multicolumn{6}{|l|}{ Wife's education } \\
\hline None & 980 & 22382 & 43.79 & 1.00 & 1.00 \\
\hline Koranic education & 2689 & 75949 & 35.41 & 0.81 (0.75 to 0.87$)$ & $0.85(0.76$ to 0.96$)$ \\
\hline Any formal & 725 & 26167 & 27.71 & $0.63(0.57$ to 0.70$)$ & $0.76(0.67$ to 0.87$)$ \\
\hline 1 to 4 years formal & 437 & 14970 & 29.19 & $0.67(0.60$ to 0.75$)$ & 0.79 (0.69 to 0.91$)$ \\
\hline $\begin{array}{l}5+\text { formal } \\
\text { Religion }\end{array}$ & 288 & 11197 & 25.72 & $0.59(0.52$ to 0.67$)$ & 0.77 (0.66 to 0.91$)$ \\
\hline Muslim & 3705 & 108089 & 34.28 & 1.00 & 1.00 \\
\hline Hindu & 689 & 16409 & 41.99 & 1.22 (1.13 to 1.33 ) & $1.12(1.00$ to 1.25$)$ \\
\hline \multicolumn{6}{|l|}{ Male occupation } \\
\hline Skilled & 1034 & 36541 & 28.30 & $0.78(0.72$ to 0.82$)$ & $0.89(0.83$ to 0.96$)$ \\
\hline Unskilled & 3171 & 85978 & 36.88 & 1.00 & 1.00 \\
\hline None & 43 & 1012 & 42.49 & $1.15(0.85$ to 1.56$)$ & $1.03(0.76$ to 1.39$)$ \\
\hline Disabled & 146 & 967 & 150.98 & 4.09 (3.47 to 4.83 ) & $3.13(2.64$ to 3.70$)$ \\
\hline \multicolumn{6}{|l|}{ Area of residence } \\
\hline Intervention & 2204 & 64852 & 33.99 & 1.00 & 1.00 \\
\hline Comparison & 2190 & 59646 & 36.72 & 1.08 (1.02 to 1.15$)$ & 1.09 (1.02 to 1.15$)$ \\
\hline \multicolumn{6}{|l|}{ Marital status } \\
\hline Married & 4100 & 119623 & 34.27 & 1.00 & 1.00 \\
\hline Widowed & 285 & 4662 & 61.13 & 1.78 (1.58 to 2.01$)$ & 1.24 (1.09 to 1.40$)$ \\
\hline Divorced & 9 & 213 & 42.25 & 1.23 (0.64 to 2.37$)$ & $0.98(0.51$ to 1.89$)$ \\
\hline \multicolumn{6}{|c|}{ Percentage of children surviving } \\
\hline $75.0-100$ & 2282 & 71322 & 32.00 & 1.00 & 1.00 \\
\hline $50.0-74.9$ & 1651 & 43288 & 38.14 & $1.19(1.12$ to 1.27$)$ & 1.11 (1.04 to 1.18$)$ \\
\hline $0-49.9$ & 461 & 9888 & 46.62 & $1.46(1.32$ to 1.61$)$ & $1.26(1.13$ to 1.40$)$ \\
\hline
\end{tabular}

*Per 1000 person years of observation. †Adjusted for age, time period, parity, and all other factors in the table. 
of migrant households from our sample may have resulted in the sample being poorer and less educated than the general population of Matlab adult men. In such a sample, however, the independent effects of women's education are even the more surprising and noteworthy, as they are unlikely to act through increased autonomy or access to financial resources as may be the case for the migrants' wives.

The pathways through which the effects of education are mediated are not well understood..$^{22}{ }^{23}$ In developing countries, it has been argued that maternal education may reduce child mortality or fertility through increasing the prospects of income $^{22}$ or employment ${ }^{25}$ but as discussed above this is unlikely in rural Bangladesh. Education may also affect preventive health behaviours including use of preventive health services, or encourage greater cooperation with curative health services. ${ }^{24} 38$ While domestic hygiene and eating practices have been shown to improve with educational status in rural Bangladesh, ${ }^{39}{ }^{40}$ the use of formal health care remains restricted. Over $50 \%$ of adults live five miles or more from a health complex that provides inpatient care $^{41}$ and local health care facilities tend to be inadequately staffed, with insufficient supplies of equipment and drugs. ${ }^{42}$ Educated parents may be more likely than uneducated parents to seek care outside the home when their children are sick, but care tends to be sought from traditional healers or untrained drug sellers who often provide inappropriate treatment. ${ }^{43}$ Increasing use of formal health care by the educated is thus unlikely to play an important part in reducing adult mortality. In a setting where men often consult healthcare practitioners on behalf of their wives ${ }^{43}$ the effect of education on contact with health services may be particularly limited in women.

It has also been suggested that maternal education reduces child mortality through raising the status of women within the home. ${ }^{24}{ }^{44}$ Educated women in rural Bangladesh certainly have more domestic autonomy and are accorded more prestige. $^{43}$ This enhanced status may give women more access to household resources than they would otherwise have, with a corresponding benefit to their survival. ${ }^{21}$ Marriage to an educated woman may increase the husband's survival in rural Bangladesh because women are the primary caretakers of their elderly husbands. If educated, these women may improve their husbands' survival in the same way as they increase their children's, for example by gaining better access to information networks or adopting healthier habits. $^{42}$

To our knowledge, this is the first study in the developing world to show that educating women can have a strong and independent effect on male mortality. Literature from affluent societies is also sparse, with inconsistent effects of wife's education seen for male mortality ${ }^{45} 46$ and cardiovascular disease..$^{47-49}$ The magnitude of the independent effect of female education in this study adds support to the hypothesis that individual resources may be the most important determinant of elderly mortality in developing countries. ${ }^{421}$ In other words, not everyone in a richer household is necessarily better off, and the key to understanding health may be individual rather than joint assets.

The apparently beneficial effects of Koranic education on mortality in women (but not in men) are not easy to interpret. Involvement in religious activities has been associated with lower mortality in developed countries, ${ }^{50}$ but we know of no study showing an independent effect of Koranic education in developing countries. Children in Matlab attend Koranic schooling for a few hours each day for two or three years. They learn to read the Koran, and are taught the rules of prayer and moral values. Whether or how this may affect mortality in later life is uncertain. Children who do not attend any schooling (that is, not even Koranic schooling) are also likely to be from the most deprived families, and we may have failed to fully account for this.

The higher mortality among the widowed, divorced, and Hindus is consistent with previous research, and is thought to be attributable in part to the social exclusion faced by these minority groups. ${ }^{38}{ }^{30}$ However, the higher mortality of men in the comparison areas after accounting for differentials in socioeconomic status is unexpected, although consistent with one previous study. ${ }^{8}$ Interventions in Matlab have never explicitly targeted subjects older than those of reproductive age, and the free access to treatment for diarrhoeal diseases at the Matlab clinic is open to all members of the community, whether they live in the intervention or comparison areas. ${ }^{27}$ This finding is difficult to interpret, but may suggest that there is a benefit to the whole population of intensive surveillance and research attention despite the focus of interventions on small sections of the community.

The educational and other social differentials in mortality were substantial given the apparent homogeneity of this poor rural agrarian population, none of whom have obvious means by which to influence their chances of survival. Our data also support the finding that primary education is sufficient to improve health status in developing countries, ${ }^{22}{ }^{23}$ despite recent arguments that primary education alone would not have an impact. ${ }^{51}$ This study highlights the difficulties in understanding the pathways to survival, and the need for further research into the nature of social and economic gradients in adult mortality in poor countries. Our results do show, however, that education is an important predictor of mortality in its own right, as has also been found in Eastern Europe. ${ }^{52}$ Increasing the numbers in education still further is therefore important for the survival of adults in rural Bangladesh. In particular, these data provide a powerful incentive for the continued promotion of formal education of women in this setting.

\section{Authors' affiliations}

L S Hurt, C Ronsmans, Maternal Health Programme, Department of Infectious and Tropical Diseases, London School of Hygiene and Tropical Medicine, London, UK

S Saha, Health and Demographic Surveillance Programme, Public Health Sciences Division, International Centre for Diarrhoeal Disease Research Bangladesh: Centre for Health and Population Research, Bangladesh

Funding: LSH was funded by a studentship from the Medical Research Council, UK during this work, and is currently funded by the Wellcome Trust.

\section{REFERENCES}

1 Davey Smith G, Shipley MJ, Rose G. Magnitude and causes of socioeconomic differentials in mortality: further evidence from the Whitehall study. J Epidemiol Community Health 1990;44:265-70.

2 Davey Smith G, Blane D, Bartley M. Explanations for socio-economic differentials in mortality. Eur J Public Health 1994;4:131-44.

3 Rahman MO, Menken J, Foster A. Older widow mortality in rural Bangladesh. Soc Sci Med 1992;34:89-96.

4 Rahman 0 . Excess mortality for the unmarried in rural Bangladesh. Int J Epidemiol 1993;22:445-56.

5 Duncan BB, Rumel D, Zelmanowicz A, et al. Social inequality in mortality in San Paolo State, Brazil. Int J Epidemiol 1995;24:359-65.

6 Gwatkin DR. Poverty and inequalities in health within developing countries: filling the information gap. In: Leon D, Walt $G$, eds. Poverty, inequality and health. An international perspective. Oxford: Oxford University Press, 2000:217-46

7 Liang J, McCarthy JF, Jain A, et al. Socioeconomic gradient in old age mortality in Wuhan, China. J Gerontol B Psychol Sci Soc Sci 2000;55:S222-33

8 Mostafa G, van Ginneken JK. Trends in and determinants of mortality in the elderly population of Matlab, Bangladesh. Soc Sci Med 2000;50:763-71.

9 Berhane Y, Hogberg U, Byass P, et al. Gender, literacy, and survival among Ethiopian adults, 1987-1996. Bull World Health Organ 2002;80:714-20.

10 Leon DA, Walt G. Poverty, inequality, and health in international perspective: a divided world? In: Leon D, Walt G, ed. Poverty, inequality and health. An international perspective. Oxford: Oxford University Press, 2000:1-17. 
11 Leigh JP. Direct and indirect effects of education on health. Soc Sci Med 1983; 17:227-34

12 Kunst AE, Mackenbach JP. The size of mortality differences associated with educational level in nine industrialized countries. Am J Public Health 1994:84:932-7.

13 Blane D, White I, Morris J. Education, social circumstances and mortality. In: Blane D, Brunner E, Wilkinson R, eds. Health and social organization: towards a health policy for the twenty-first century. London: Routledge 1996:171-87.

14 Lantz PM, Lynch JW, House JS, et al. Socioeconomic disparities in health change in a longitudinal study of US adults: the role of health-risk behaviors. Soc Sci Med 2001;53:29-40.

15 Valkonen T. Socio-economic mortality differences in Europe. The Hague: Netherlands Interdisciplinary Demographic Institute (NIDI), 1993.

16 Mackenbach JP, Kunst AE, Groenhof F, et al. Socioeconomic inequalities in mortality among women and among men: an international study. Am J Public Health 1999;89:1800-6.

17 Kenkel KS. Health behavior, health knowledge, and schooling. Journal of Political Economy 1991;99:287-305.

18 Schrijvers CJM, Stronks K, van de Mheen D, et al. Explaining educational differences in mortality: the role of behavioral and material factors. Am J Public Health 1999;89:535-40

19 Brunner E. Education, education, education. Int J Epidemiol $2001 ; 30: 1126-8$.

20 Kilander L, Berglund L, Boberg $M$, et al. Education, lifestyle factors and mortality from cardiovascular disease and cancer. A 25-year follow-up of Swedish 50-year-old men. Int J Epidemiol 2001;30:1119-26.

21 Rahman MO. Age and gender variation in the impact of household structure on elderly mortality. Int J Epidemiol 1999;28:485-91.

22 Cleland JG, van Ginneken JK. Maternal education and child survival in developing countries: the search for pathways of influence. Soc Sci Med 1988:27:1357-68.

23 Majumder AK. Maternal factors and infant and child mortality in Bangladesh. J Biosoc Sci 1988;20:59-65.

24 Caldwell JC. How is greater maternal education translated into lower child mortality? Health Transit Rev 1994:4:224-9.

25 Khuda B, Hossain MB. Fertility decline in Bangladesh: towards an understanding of major causes. Health Transit Rev 1996;6(suppl.):155-67.

26 Simmons R, Mita R, Koenig M. Changes in women's status in Matlab. In: Fauveau V, ed. Matlab: women, children and health. Dhaka: ICDDR, $\mathrm{B}$ 1994:323-40.

27 Aziz KMA, Mosley WH. Historical perspective and methodology of the Matlab project. In: Fauveau V, ed. Matlab: women, children and health. Dhaka: ICDDRB, 1994:29-50.

28 Fauveau V. Data collection systems and datasets available in Matlab. In: Matlab: women, children and health. Dhaka: ICDDRB, 1994:51-64.

29 Davies L. The long-term effects of childbearing on the mortality of adults in Matlab, Bangladesh. [PhD thesis.] London: University of London, 2001.

30 Rahman MO. Family matters: the impact of kin on the mortality of the elderly in rural Bangladesh. Popul Stud 1999;53:227-35.

31 Rubin D. Multiple imputation for nonresponse in surveys. New York: Wlley, 1987.
32 Schafer J. Analysis of incomplete multivariate data. London: Chapman and Hall, 1997

33 Rahman MO. The impact of co-resident spouses and sons on elderly mortality in rural Bangladesh. J Biosoc Sci 2000;32:89-98.

34 Fauveau V. Matlab: Physical setting and cultural background. In: Matlab: women, children and health. Dhaka: ICDDRB, 1994:13-28.

35 Afsar R. Rural-urban migration and development: evidence from Bangladesh. In: Bilsborrow RE, ed. Migration, urbanization, and development: new directions and issues. New York: United Nations Population Fund, 1998:319-56

36 Hadi A. Overseas migration and the well-being of those left behind in rural communities of Bangladesh. Asia Pac Popul J 1999; 14:43-58.

37 Hadi A. International migration and the change of women's position among the left-behind in rural Bangladesh. Int J Popul Geogr 2001;7:53-61.

38 Caldwell JC. Routes to low mortality. Popul Dev Rev 1986;12:171-220.

39 Feachem RG. Interventions for the control of diarrhoeal diseases among young children: promotion of personal and domestic hygiene. Bull World Health Organ 1984;62:467-76.

40 Guldan GS, Zeitlin MF, Beiser AS, et al. Maternal education and child feeding practices in rural Bangladesh. Soc Sci Med 1993;36:925-35.

41 Mitra S, Al-Sabir A, Cross A, et al. Bangladesh Demographic and Health Survey 1996-1997. Dhaka and Calverton, MD: National Institute of Population Research and Training (NIPORT), Mitra and Associates, and Macro International, 1997.

42 Rahman AS. Utilization of primary health care services in rural Bangladesh: the population and provider perspective. [PhD thesis.]. London: University of London, 2000.

43 Alam N. Women, households and communities and the care of sick children in rural Bangladesh. [PhD thesis.]. London: University of London, 2000.

44 Santow G. Social roles and physical health - the case of female disadvantage in poor countries. Soc Sci Med 1995;40:147-61.

45 Suarez L, Barrett-Connor E. Is an educated wife hazardous to your health? Am J Epidemiol 1984;119:244-9.

46 Bosma H, Appels A, Sturmans F, et al. Educational level of spouses and risk of mortality: the WHO Kaunas-Rotterdam Intervention Study (KRIS). Int J Epidemiol 1995;24:119-26.

47 Haynes SG, Eaker ED, Feinleib M. Spouse behavior and coronary heart disease in men: prospective results from the Framingham heart study. I. Concordance of risk factors and the relationship of psychosocial status to coronary incidence. Am J Epidemiol 1983;118:1-22.

48 Strogatz DS, Siscovick DS, Weiss NS, et al. Wife's level of education and husband's risk of primary cardiac arrest. Am J Public Health 1988;78:1491-3.

49 Egeland GM, Tverdal A, Meyer HE, et al. A man's heart and a wife's education: a 12-year coronary heart disease mortality follow-up in Norwegian men. Int J Epidemiol 2002;31:799-805.

50 McCullough ME, Hoyt WT, Larson DB, et al. Religious involvement and mortality: a meta-analytic review. Health Psychol 2000;19:211-22.

51 Curtin TR, Nelson EA. Economic and health efficiency of education funding policy. Soc Sci Med 1999:48:1599-611.

52 Marmot $M$, Bobak $M$. International comparators and poverty and health in Europe. BMJ 2000;321:1124-8. 